\title{
BEHAVIORAL AND PARAMETRIC EFFECTS ON ENERGY CONSUMPTION THROUGH BIM, BEM, AND ABM
}

\author{
Mohamad Hajj-Hassan ${ }^{\mathrm{a}}$, Hiam Khoury ${ }^{\mathrm{a}, *}$ \\ ${ }^{a}$ American University of Beirut, Beirut 1107 2020, Lebanon
}

\begin{abstract}
Over the past years, several tools and methods have been developed to address performance-related designs and provide designers with integrative platforms to estimate building energy consumption and mitigate its impact. However, the predictions obtained through different energy modeling engines have been typically deviating from the actual energy consumption. As such, many efforts have attempted at bridging this so-called "performance gap. Nonetheless, this was conducted in a fragmented fashion whereby synchronizing the geometric exchange of Building Information Modeling (BIM) to Building Energy Modeling (BEM) was done independently from incorporating, through Agent-Based Modelling (ABM), building occupants' behavior vis-à-vis energy consumption. Therefore, this paper merges the aforementioned approaches and presents work targeted at assessing the diverse and dynamic energy-use behavior of occupants using BIM, BEM and ABM. To that end, a simulation environment was developed to study both the parametric design and behavioural factors. The design parameters included within a BIM model were utilized to set the thermal zone, the internal zone gains were defined using $A B M$, and resulting data was exported as an input data file to EnergyPlus. Several experiments have been conducted for the case of an academic office and results of the energy analysis highlighted a variation of up to $11 \%$ as compared to static occupant behavioral patterns generally adopted.
\end{abstract}

(C) 2018 The Authors. Published by Diamond Congress Ltd., Budapest University of Technology and Economics Peer-review under responsibility of the scientific committee of the Creative Construction Conference 2018.

Keywords: ABM; BIM; BEM ; energy; simulation;

\section{Background}

In recent years, the debate surrounding BIM and BEM has been aggregated by the widely accepted "performance gap". The efforts to bridge this gap were channeled towards synchronizing the data exchange between the architectural model and the energy model. According to Hyun et al. [1], BIM can play a key role in improving the consistency of construction information related to building energy analysis. Through the use of BIM, the process of creating an energy model can be easily automated. Consequently, geometry and other assumptions detailed in the architectural model remain consistent and are not subject to interpretation or improper simplification. Furthermore, BEM has always relied on performance-based compliance paths, whereby a building's proposed design must not exceed the energy consumption of a similar reference building modeled with the prescriptive inputs from the code [2, 3]. For example, ANSI/ASHRAE/IES Standard 90.1-2016 [3] provides trade-off schedules and densities for occupancy, lighting, equipment, and thermostat set points for different types of buildings. However, and given that each building has its unique features and operational conditions, codes and standards fail to provide a realistic schedule tailored to each building. On that account, design engineers (i.e. architects or service consultants) fail to notice the connection between building technical features (e.g. volume, orientation, shading devices, etc.) and the behavioral patterns and operating profiles of the occupants. The aftermath is two spatially competing models, BIM 
vs. BEM, that ignores the complexity that occupants' behavior add to the estimation of building energy consumption activities [4-7]. In addition to energy-behavior synergy, recent studies in commercial and residential buildings have concluded that the behavior of occupants within an indoor environment has a dual effect on both the overall building energy use and occupants' satisfaction with the indoor environmental quality (IEQ) [2, 8]. Prone to this give-andtake relationship between energy and comfort, researchers no longer have the luxury to treat occupant-related variables as boundary conditions; in other words, making default assumptions about occupants' behavior in energy modeling is bygone [9]. As such, the process of simulating occupant behavior has been gaining an increasing attention in recent simulation research with several methods being implemented to mimic occupants' behavior in buildings. For instance, Nassar and Elnahas [10] used the random walk approach to assess the topology of space design in terms of occupants' movement. Furthermore, Virote and Neves-Silva [11] explored the applicability of stochastic models to represent the space occupancy and the occupant's behavior. On the other hand, ABM has been widely used to simulate the interaction of occupants with their environment and with other agents [12-15] and has proven very promising in reflecting occupant's sensation, perception, inference, and interaction. For instance, Lee and Malkawi [13] used ABM to allow agents to adapt to their environment by making reasonable behavioral decisions based on their comfort. Similarly, Barakat and Khoury [14] employed an agent-based framework to study occupant multi-comfort level for building energy optimization.

From what has been presented, some efforts attempted at coupling the two spatially competing models, BIM and BEM, but this was conducted in a fragmented fashion whereby synchronizing the geometric exchange of BIM to BEM was done independently from incorporating, through Agent-Based Modelling (ABM), building occupants' behavior vis-à-vis energy consumption. Therefore, this paper presents a holistic framework targeted at assessing the diverse and dynamic energy-use behavior of occupants using BIM, BEM and ABM. The contributions of the research presented in this paper thereby lie in : (1) creating a BIM model of the office space that employs the visual programming language (VPL) to automate the parametric and behavioral data exchange with BEM and ABM respectively, (2) developing an agent-based model (ABM) whereby an autonomous agent interacts with its environment and makes behavioral decisions based on thermal and visual comfort levels, 3) documenting the behavioral decisions and exporting them to the BEM model to generate annual energy consumption, and (4) validating the proposed BIM-BEM-ABM framework by comparing simulated results with results obtained from a survey conducted with occupants of the same environment as the one simulated.

\section{Methodology}

In order to achieve the objectives of this research study, the proposed methodology addresses issues in two main task areas, namely: (1) Design and implementation of a thermal and visual environmental survey, and (2) Development of a BIM-BEM-ABM framework using Revit-Dynamo, EnergyPlus, and Anylogic.

\subsection{Satisfaction Survey Design and Implementation}

Satisfaction surveys are invaluable diagnostic tools used to provide detailed insight into the building daily operations through occupant feedback. In this study, the purpose behind conducting a thermal and visual environmental survey is to directly acquire about the occupants comfort levels, which can be used as a verification tool in the modeling part. As such, a thermal and a visual satisfaction survey is constructed following the guidelines provided in ANSI/ASHRAE Standard 55-2013 [16] and is divided in three sections. The first section includes general information pertaining to the room number, desk number, and type of controls available in the given space (e.g. window shades, thermostat, light switches). In the second section, the occupants are asked to report their overall thermal and visual experience on a 7-point semantic differential scale with choices ranging from -3 (very satisfied) to +3 (very dissatisfied). In the event where respondents vote dissatisfied to either of the visual or thermal subsections, they are then asked to move to the third section. In this latter section, respondents are asked about their expected behavior towards their dissatisfied/discomfort state (i.e. visually dissatisfied, thermally dissatisfied hot, and thermally dissatisfied cold) given four control features (switches, shades, thermostat and clothing insulation level). If an occupant opts to adjust the thermostat, he/she is then asked to input the set-point that would adjust their thermally dissatisfied state.

In this study, an open space office, having a total floor area of $120 \mathrm{~m}^{2}$ and a height of $4 \mathrm{~m}$, was surveyed in a medium-size academic office building (Figure 1). The space counted 18 occupants with a response rate of 83\%; 
exceeding the rate set by ANSI/ASHRAE Standard 55 [16] ( $80 \%$ for under 20 solicited occupants). However, as the sample size surveyed is considered small, 15 additional occupants were surveyed from an adjacent office that has the same spatial characteristics. The probability of occupants satisfied was then predicted by dividing the number of votes falling between "just satisfied" and "very satisfied," by the total number of votes.

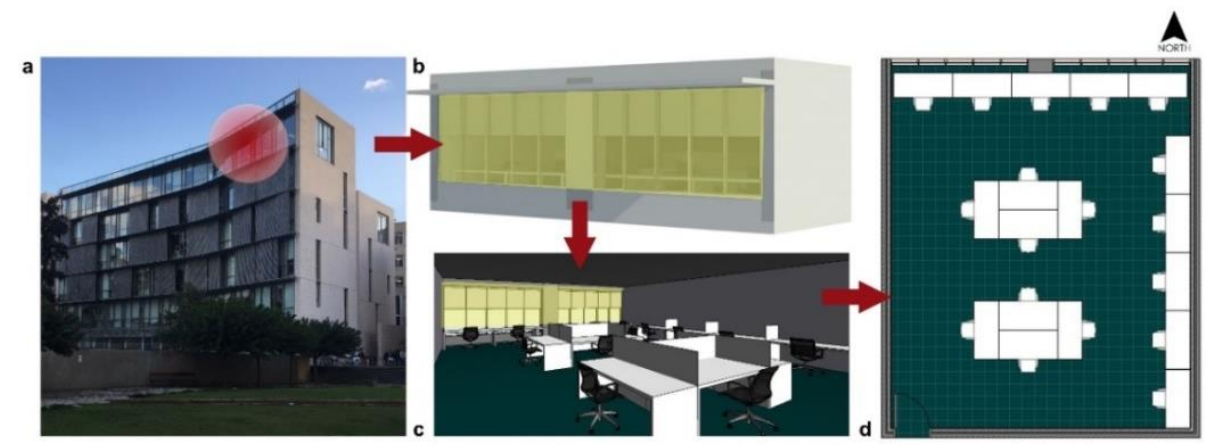

Fig. 1. (a) Actual office building; (b) Revit model for the selected office; (c) Internal camera view; (d) Internal space distribution.

\subsection{BIM-BEM-ABM Framework Development}

Conventionally, extracting input data from BIM for energy modeling has been relying on two main methods; namely the Industry Foundation Class (IFC) and the Green Building XML (gbXML) [17, 18]. However, users of these methods have little control over how data files are created or loaded. To address this, Visual Programming Language (VPL) has been introduced to the BIM-BEM spectrum [19]. VPL allows novice users in programming to create computer programs by building visual relationships between elements within a user friendly interface [20]. Accordingly, this part of the paper builds on previous work that presented a graphical visual programing interface, DynamoPlus, to induce BIM-BEM interoperability[22]. Yet, this data extraction covered only the geometric aspect while the dynamic occupant integration with the building system had to be assumed according to an energy code. Therefore, this paper challenges the aforementioned interface and presents a holistic approach targeted at assessing the diverse and dynamic energy-use behavior of occupants using BIM, BEM and ABM (Figure 2).

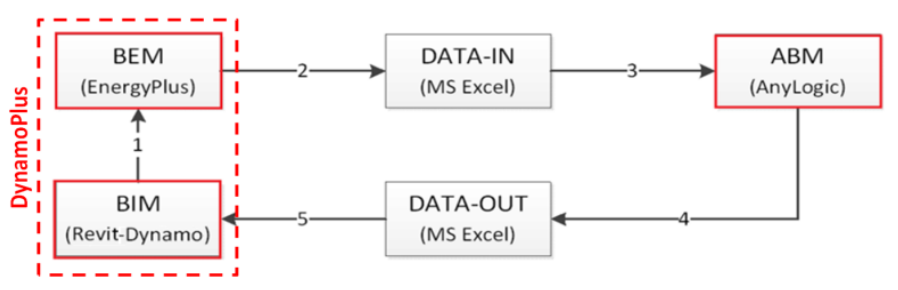

Fig. 2. BIM-BEM-ABM framework.

The first step towards setting up this trinity starts by building an architectural BIM model (Figure 2). Next, with reference to Hajj-Hassan and Khoury [22], DynamoPlus works on creating three major "Objects" for the simulation engine, EnergyPlus, namely the "Zone Definition, Zone Loads-Internal Gains, and Zone Loads-Outdoor Air [22]. The second step initiates the first energy run from EnergyPlus (i.e. step 2 in Figure 2). In this case, six input data files (IDF) [22] are created in order to generate the required data/input needed to run the ABM model (i.e. step 3 in Figure 2). More specifically, the thermal and illumination environmental factors are simulated for a whole year (8760 hours) to determine the mean radiant temperature (tr), natural daylighting lux, and glare index. Furthermore, each of these parameters (tr, lux, and glare) were obtained with respect to two behavioral decisions, "shades on" or "shades off", at a specified reference point in the Revit model, which in our case was the working level around the center of the space. The second energy run is initiated after ABM exports the behavioral parameters as "DATAOUT" into an Excel sheet (step 4 in Figure 2). At this stage, a new graph is added to the 'DynamoPlus' architecture (i.e. step 5 in Figure 2). The graph reads the exported data from ABM and lists them in a syntax readable by EnergyPlus. The rationale behind this step is the ability of the VPL, employed by the BIM component, to transform time-dependent input parameters into schedules that contain occupant behavioral decisions at different time intervals. Hence, the generic "IDF" file that was generated according to default schedules described by the user or ANSI/ASHRAE/IES Standard 90.1-2016 is now redefined to include additional schedule-related "Objects", 
particularly "ScheduleTypeLimits", "ScheduleCompact", and "ZoneControl:Thermostat". Understanding how these "Objects" operate in conjunction with the overall energy simulation environment is key to generating realistic results that mimic real-life scenarios; another shortcoming encountered when resolving energy simulation interfaces and plugins [23].In fact, this group of objects allows the user to influence scheduling of many items (such as occupancy density, lighting, thermostatic controls) and to control the switches and shades status at each time step. For the first object, discrete numeric values were set as "control type schedules" for the thermostat, internal shades, and switches. Besides formulating an energy model based on the simulated behavior of occupants, a baseline building design was modeled to ASHRAE 90.1 prescriptive requirements as a reference building. The goal behind developing such a reference building was to compare it with the pre-set schedule assumptions' sensitivity to changes in occupancyrelated behaviors and ultimately shed light on some of the shortcomings of occupant modeling requirements in the above mentioned energy code. In this model, the thermostat temperature set-points are defined as shown in Figure 3, the Daylighting:Control object is used to determine how much the electric lighting can be reduced, and the shades are modeled to be lowered when the solar transmitted energy exceeds $100 \mathrm{watt} / \mathrm{m}^{2}$ and then remain lowered for the rest of the day.

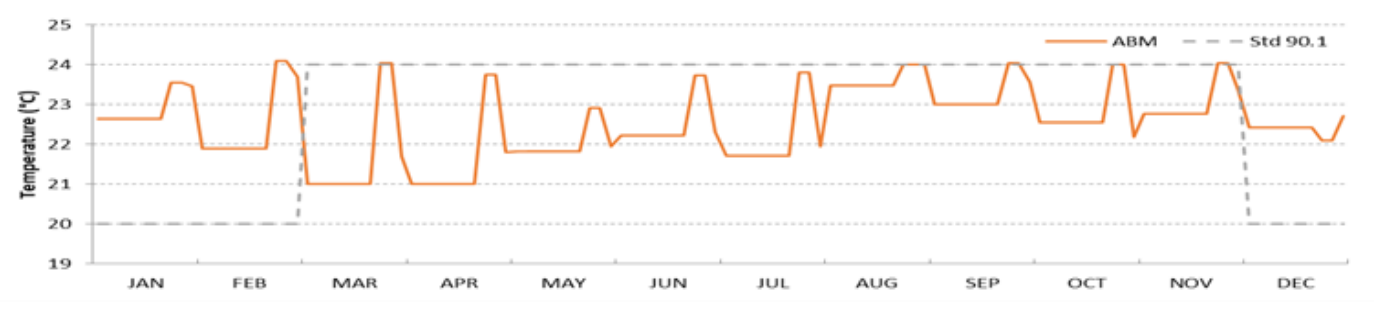

Fig. 3. Typical day/month for simulated behavior of thermostat set-point.

It is worth noting again that the BEM framework component aims at creating an energy model that calculates the energy consumption of the selected office space. Additionally, the methods used to formalize the EnergyPlus "Objects" are highlighted to explain the transformation of time-dependent ABM parameters into schedules that contain occupant behavioral decisions at different time intervals. According to ASHRAE Standard 169-2013 [24], the climate zone for the area under study (i.e. Beirut, Lebanon) is " $2 \mathrm{~A}$ " which is defined as Hot-Humid. The weather file used for the simulation was obtained from the National Center for Environmental Information (NCEI) and is based on a Typical Meteorological Year (TMY) for years 1993 to 2016 [25]. The values for the different envelope components were provided by building operators and are summarized in Table 1 . The glazed surface is oriented towards the North with a window to wall ratio (WWR) of 0.9 and an external shading device with a projection factor (PF) of 0.45 .

Table 1. Building Envelope requirements

\begin{tabular}{ll}
\hline Opaque Elements U-values & Fenestration Elements \\
\hline Roof $=0.49 \mathrm{w} / \mathrm{m} 2 \mathrm{k}$ & Assembly U-value $=3.04 \mathrm{w} / \mathrm{m} 2 \mathrm{k}$ \\
Mass wall $=0.45 \mathrm{w} / \mathrm{m} 2 \mathrm{k}$ & Assembly SHGC $=0.55$ \\
Floors $=0.6 \mathrm{w} / \mathrm{m} 2 \mathrm{k}$ & Assembly Min VT $/ \mathrm{SHGC}=1.2$ \\
\hline
\end{tabular}

Another framework component warranting some further discussion is the aforementioned multi-comfort ABM model that was created using Anylogic, a java-based software that allows the user to develop custom Java codes and integrate them in prebuilt simulation blocks[27]. A prerequisite for the ABM model consists of conceiving a wholebody thermal-balance comfort (WBC) model to predict thermal comfort. This model predicts the thermal sensation (predicted mean vote, PMV) and percent dissatisfaction (predicted percent of dissatisfied, PPD) for a group of people based on measurements of the physical parameters in the environment[28]. On the contrary, no adequate human visual comfort model is found to support consensus-based design recommendations[29]. Accordingly, visual comfort was assessed on the basis of meeting a minimum horizontal illumination of 500 lux while not exceeding a discomfort glare index (DGI) of 21 [30, 31]. Once the comfort principals were put in place, the multi-comfort ABM model was then realized (Figure 4) with two primary objectives: (1) Predict and verify the probabilities or likelihood of occupants choosing actions that were examined in the satisfaction survey and (2) Export the learning process of the representative occupant as schedules to the BEM model. 


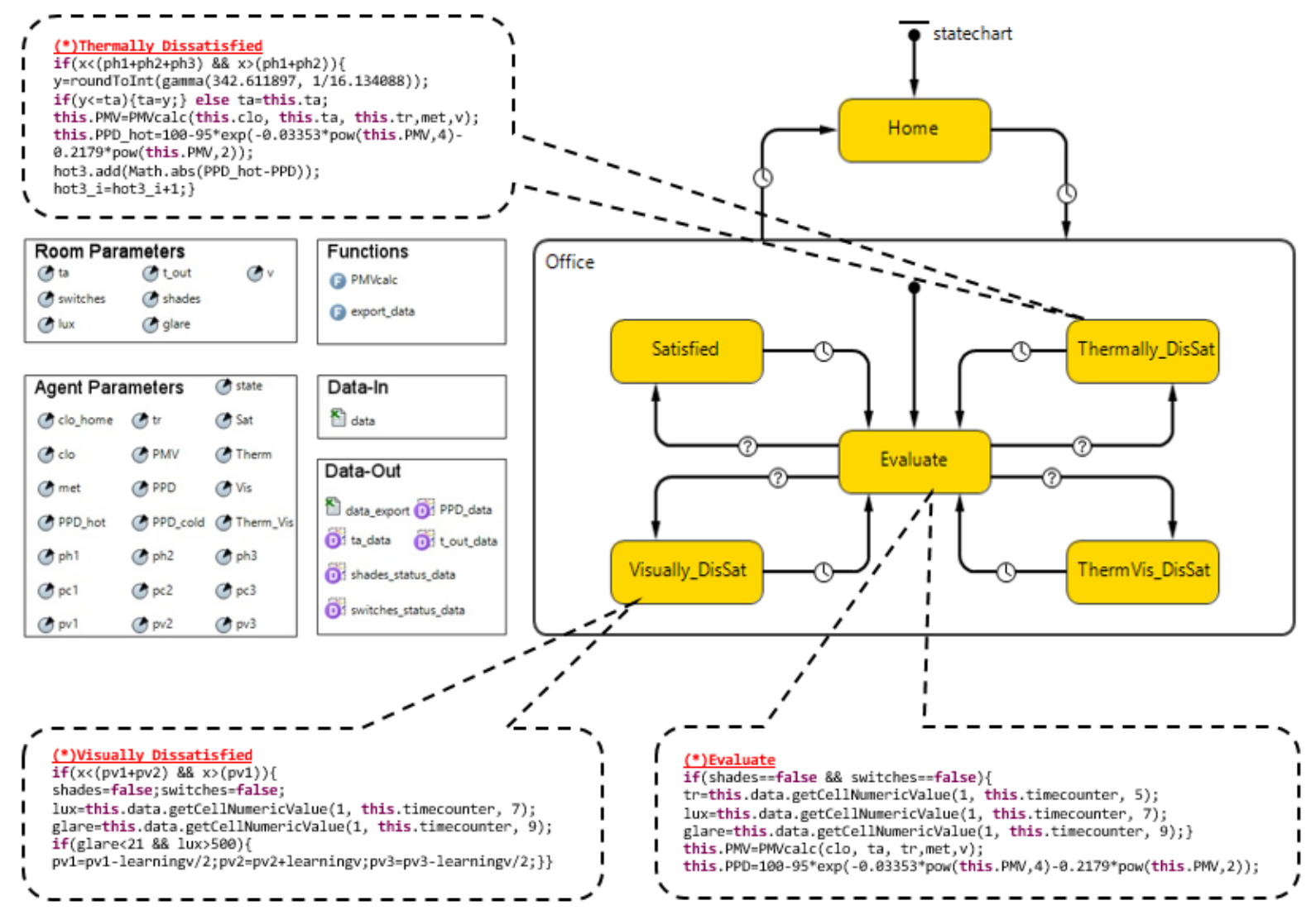

Fig. 4. Multi-Comfort Occupant Agent State-chart

The simulation takes place over a whole year while taking into consideration the effect of each month on the pre-set thermostat temperature and the occupants' choice of their initial clo-level (clo_home) at the beginning of each day. The thermostat temperature for each month is based on the requirements set in ANSI/ASHRAE/IES Standard 90.1 (Figure 3). The clo_home parameter, shown in Figure 4 under Agent Parameters, is determined for a representative occupant as a function of outdoor air temperature at 06:00 a.m. (Figure 5). The clo levels are adjusted to higher values to account for dress code adopted in Lebanon and as described in ASHRAE-55 clothing ensembles. Additionally, one of the important assumptions considered in the modeling process is the use of a representative occupant to account for all the occupants present in the office space. This is considered acceptable due to the following: (1) ASHRAE-55 states that, when the WBC method is used and occupants are free to adjust their clothing in response to the thermal conditions, it is feasible to assume a single representative occupant with an average clolevel value representing multiple individuals [16], (2) as several occupants working in the chosen office space are considered to have a metabolic rate around $60 \mathrm{~W} / \mathrm{m}^{2}$, common to office reading, writing, and typing activities, it is thereby suitable to assume a single representative occupant with an average metabolic rate value representing multiple occupants, and (3) the learning behavior of the representative occupant is based on decreasing the PPD which is the index that establishes a quantitative prediction of the percentage of thermally dissatisfied people.

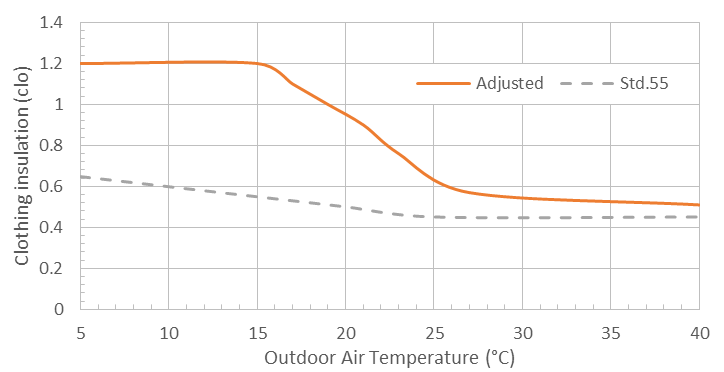

Fig. 5. Adjusted and ASHRAE'Ss Std. 55 representative clothing insulation as a function of outdoor air temperature at 6:00 a.m. 
Carrying on, each day starts at 8:00 AM and ends at 6:00 PM with Saturdays and Sundays excluded from the simulation process. The time unit for the model is selected to be hours with two agents, occupant and room. The occupant agent adjusts its overall state (i.e. satisfied, thermally dissatisfied, visually dissatisfied, or thermally/visually dissatisfied) based on the room parameters (e.g. thermostat set-point, lux level, etc.) and probabilities of actions taken by the agent. Figure 4 depicts the statechart of the occupant agent in particular. In this case, two main states exist, Home and Office. In the home state, the agent performs no actions and waits for 14 hours before it is allowed to enter the "Office" state. Once in the office state, the agent starts transitioning between different internal states. These transitions are either time-triggered or condition-triggered. The agent first enters into the "Evaluate" state to determine its current thermal and visual comfort level and then calculates the PPD. The comfort levels are determined from the parameters read from the "DATA-IN" sheet (Figure 2). Given the overall state, the agent then exits with a condition-triggered transition to any of the other internal states. For example, if the $|\mathrm{PMV}|>0.5$ and lux $>500$, the agent enters the "Thermally_DisSat"state. In this new state, the agent decides whether it is dissatisfied thermally hot or cold and then takes actions based on initial pre-set equal probabilities, in this case $33 \%$. After taking an action, the occupant agent determines the benefit obtained by calculating the difference between the initial and final PPD. This helps the agent develop a learning behavior that decreases the overall percentage of dissatisfied and accordingly adjusts the probabilities. The agent stays for 1 hour in the state "Thermally_DisSat" before it is allowed to exist back to "Evaluate" and the cycle resumes for 8760 time steps.

\section{Experimental Results and Discussion}

Survey results (Table 2) show that $23 \%$ of occupants are thermally dissatisfied whereas $17 \%$ are visually dissatisfied - a reasonable outcome given that the office building is oriented towards the north (Figure 1). Moreover, the number of occupants taking specific behavioral actions to adjust their comfort level were categorized and counted as shown in Table 2.

Table 2. Percentage of occupant/agents taking specific actions when thermally and visually dissatisfied.

\begin{tabular}{|c|c|c|c|}
\hline \multirow[t]{2}{*}{$\underline{\text { Actions }}$} & \multirow[t]{2}{*}{$\underline{\text { Survey Values }}$} & \multicolumn{2}{|c|}{$\underline{\text { Simulation Values }}$} \\
\hline & & Mean & $\mathrm{SD}$ \\
\hline \multicolumn{4}{|l|}{ Thermally Dissatisfied (Hot) } \\
\hline ph1: Clo-level \& Thermostat-set point & $63.3 \%$ & $65.3 \%$ & 1 \\
\hline ph2: Clo-level & $20 \%$ & $16.5 \%$ & 0.47 \\
\hline ph3: Thermostat-set point & $16.7 \%$ & $18.2 \%$ & 0.92 \\
\hline \multicolumn{4}{|l|}{ Thermally Dissatisfied (Cold) } \\
\hline pc1: Clo-level \& Thermostat-set point & $20 \%$ & $21.9 \%$ & 0.7 \\
\hline pc2: Clo-level & $57 \%$ & $55.3 \%$ & 1.18 \\
\hline pc3: Thermostat-set point & $23 \%$ & $22.8 \%$ & 0.68 \\
\hline \multicolumn{4}{|l|}{ Visually Dissatisfied } \\
\hline pv1: Switches On \& Shades On & $53 \%$ & $45 \%$ & 2.89 \\
\hline pv2: Switches Off \& Shades Off & $7 \%$ & $8.6 \%$ & 0.7 \\
\hline pv3: Switches On \& Shades Off & $40 \%$ & $53.6 \%$ & 2.88 \\
\hline
\end{tabular}

It was found, that occupants tend to choose between three options when they are thermally dissatisfied. They would either: (1) adjust their clothing insulation (clo-level) and thermostat set-point (ph1 or pc1), (2) adjust only their clolevel (ph2 or pc2), or (3) change the thermostat set-point (ph3 or pc3). Furthermore, when visually dissatisfied, occupants tend to choose between three different options related exclusively to the shades and switches statuses. The probabilities of occupants choosing each of these actions are also presented in Table 2. As shown, 63.3\% of occupants choose "ph1" when thermally dissatisfied during a hot weather. However, in a cold weather, the majority of occupants (57\%) choose only to adjust their clo level.

On the other hand, the framework simulated results came very close to the values obtained from the satisfaction survey conducted in the open space office environment (Table 2). Additionally, the dynamic behavioral patterns shown in Figure 6 were obtained from the ABM model in the form of logged data and converted into typical daily schedules over 12 months. These patterns are a representation of the simulated values for PPD and Thermostat set points. Thirty simulations were logged and used to estimate the building energy consumption in each run. The 
histograms for the simulated satisfied hours and building energy consumption are presented in Figure 7. Moreover, a Shapiro-Wilk test failed to reject the null hypothesis that the data came from a normally distributed set. A right tailed t-test was then used to compare the true mean of the simulated set with that of the reference building's total, cooling, and heating energy consumption (e.g. 106.39, 62.28, and $17.96 \mathrm{GJ} / \mathrm{yr}$ respectively). In this case, the following null hypothesis was tested: "the mean difference between the true and reference value is zero" and the alternative hypothesis was set as: "the true mean of the simulated set was greater than the reference energy values". As the pvalue obtained for all three tests was 2.2e-16, which is less than the chosen confidence level (0.05), the null hypothesis was rejected. Accordingly, there is sound evidence that the energy consumption as a function of occupant behavior is greater than that of the static occupant behavioral patterns adopted by the current energy codes.

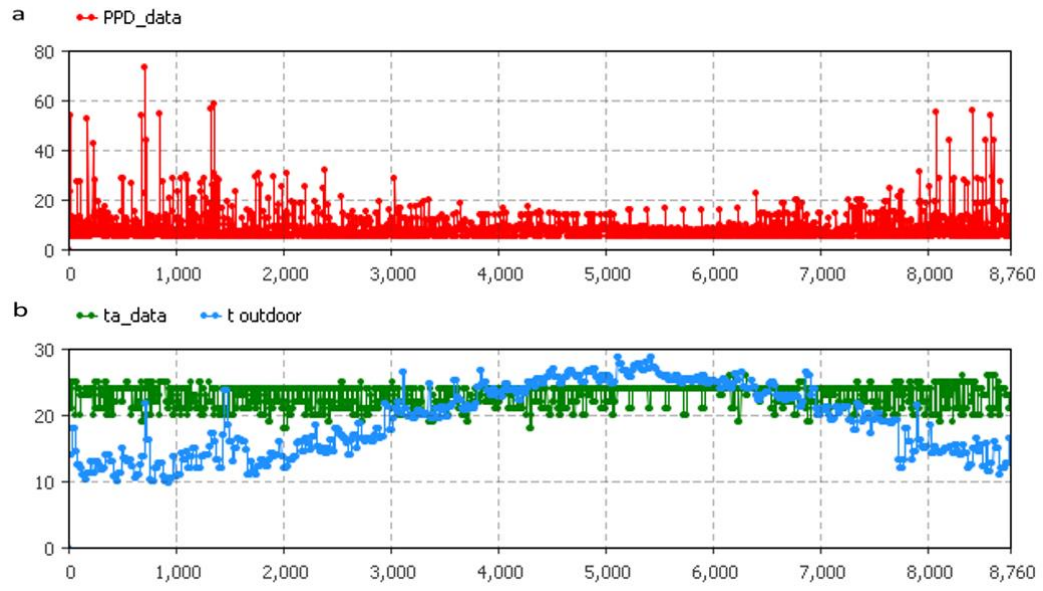

Fig. 6. (a) PPD and (b) Thermostats set-point simulated values over the whole year.
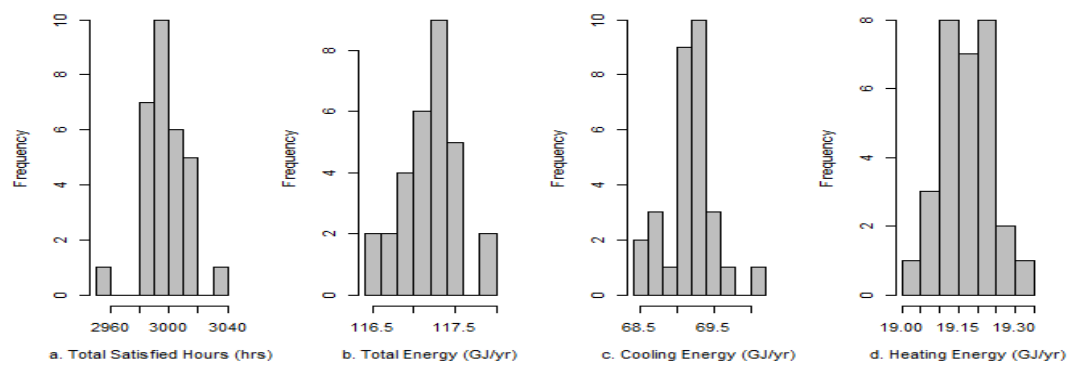

Fig. 7. Histograms of simulated (a) Total satisfied hours, (b) Total Energy consumption, (c) Cooling energy, and (d) Heating energy.

\section{Conclusion and Future Work}

The set of models discussed in this paper are an attempt at simulating the impact that occupants may have on a building in terms of energy consumption. In particular, the ABM model presents a novel approach towards predicting the probabilities of actions that occupants might select to enhance both of their visual and thermal comfort levels. As a matter of fact, the simulated results came very close to the values obtained from the satisfaction survey conducted in an open space office environment. Additionally, the paper constitutes an eye-opener for practitioners adopting occupant modeling requirements from current codes and standards, emphasizes the fact that static schedules do not represent all building types, and is considered a major contributor to the performance gap between simulated and measured energy use. Moreover, another contribution lies in addressing the performance gap via a BIM-VPL interface that acts as a communicating hub between BEM and ABM. The final emulation of this array of models was documented on an office space with the energy analysis results highlighting variations with up to $11 \%$ as compared to static behavioral patterns generally adopted. Future research is needed to cover other IEQ factors such as air quality and acoustics and cover different categories of occupants. Additional work is needed as well to study the effect of different building parameters on energy vs. comfort optima. Such studies will look to test the validity of the proposed models in accounting for different technical aspects of a building including orientation, skin treatment and material selection. 


\section{Acknowledgements}

The authors gratefully acknowledge both Munib and Angela Masri Institute of Energy and Natural Resources and AUB's University Research Board (URB) Any opinions, findings, conclusions, and recommendations expressed by the authors in this paper do not necessarily reflect the views of the Masri Institute or URB.

\section{References}

1. Hyun, S., L. Marjanovic-Halburd, and R. Raslan, Investigation into informational compatibility of Building Information Modelling and Building Performance Analysis software solutions. WIT Transactions on The Built Environment, 2015. 149: p. 543-553.

2. Ouf, M. and W. O'Brien, Occupant Modeling for Code Compliance and Incentive Programs. ASHRAE Journal, 2018. 60(2).

3. ASHRAE, ANSI/ASHRAE/IES Standard 90.1: Energy Standard for Buildings Except Low-Rise Residential Buildings. 2016, American Society of Heating, Refrigerating and Air-Conditioning Engineers: Atlanta.

4. Delzendeh, E., et al., The impact of occupants' behaviours on building energy analysis: A research review. Renewable and Sustainable Energy Reviews, 2017. 80: p. 1061-1071.

5. Haldi, F. and D. Robinson, The impact of occupants' behaviour on building energy demand. Journal of Building Performance Simulation, 2011. 4(4): p. 323-338.

6. Feng, X., D. Yan, and T. Hong, Simulation of occupancy in buildings. Energy and Buildings, 2015. 87: p. 348-359.

7. Sun, K. and T. Hong, A framework for quantifying the impact of occupant behavior on energy savings of energy conservation measures. Energy and Buildings, 2017. 146: p. 383-396.

8. Langevin, J., J. Wen, and P.L. Gurian, Simulating the human-building interaction: Development and validation of an agent-based model of office occupant behaviors. Building and Environment, 2015. 88: p. 27-45.

9. O'Brien, W., et al., International survey on current occupant modelling approaches in building performance simulation. Journal of Building Performance Simulation, 2017. 10(5-6): p. 653-671.

10. Nassar, K. and M. Elnahas, Occupant dynamics: Towards a new design performance measure. Architectural Science Review, 2007. 50(2): $\mathrm{p}$. $100-105$

11. Virote, J. and R. Neves-Silva, Stochastic models for building energy prediction based on occupant behavior assessment. Energy and Buildings, 2012. 53: p. 183-193.

12. Azar, E. and C.C. Menassa, Agent-based modeling of occupants and their impact on energy use in commercial buildings. Journal of Computing in Civil Engineering, 2011. 26(4): p. 506-518.

13. Lee, Y.S. and A.M. Malkawi, Simulating multiple occupant behaviors in buildings: An agent-based modeling approach. Energy and Buildings, 2014. 69: p. 407-416.

14. Barakat, M. and H. Khoury. An agent-based framework to study occupant multi-comfort level in office buildings. in Winter Simulation Conference (WSC), 2016. 2016. IEEE.

15. Ahn, K.-U. and C.S. Park, Different occupant modeling approaches for building energy prediction. Energy Procedia, 2016. 88: p. $721-724$.

16. ASHRAE, ANSI/ASHRAE Standard 55: Thermal environmental conditions for human occupancy. 2013, Atlanta: American Society of Heating, Refrigerating and Air-Conditioning Engineers.

17. Kim, K. and J. Yu, BIM-based building energy load calculation system for designers. KSCE Journal of Civil Engineering, 2016. 20(2): p. 549-563.

18. Dimitriou, V., et al., BIM enabled building energy modelling: development and verification of a GBXML to IDF conversion method. 2016.

19. Seghier, T.E., et al., Building Envelope Thermal Performance Assessment Using Visual Programming and BIM, based on ETTV requirement of Green Mark and GreenRE. International Journal of Built Environment and Sustainability, 2017. 4(3).

20. Boeykens, S. and H. Neuckermans, Visual Programing in Architecturre: Should Architects be trained as programmers? 2009.

21. Dynamo, DYNAMO BIM. 2017, Autodesk Inc.

22. Hajj-Hassan, M. and H. Khoury. DynamoPlus: Synchronizing Data Exchange between Dynamo and EnergyPlus. in International Conference for Sustainable Design of the Built Environment-SDBE London. 2017.

23. Noack, F., et al. Technical challenges and approaches to transfer building information models to building energy. in eWork and eBusiness in Architecture, Engineering and Construction: ECPPM 2016: Proceedings of the 11th European Conference on Product and Process Modelling (ECPPM 2016), Limassol, Cyprus, 7-9 September 2016. 2017. CRC Press.

24. ASHRAE, ANSI/ASHRAE Standard 169: Climatic Data for Building Design Standards. 2013, Atlanta: American Society of Heating, Refrigerating and Air-Conditioning Engineers.

25. NCEI. Climate Data Online: Dataset Discovery. 2018; Available from: https://www.ncdc.noaa.gov/cdo-web/datasets.

26. AnyLogic, AnyLogic 8 Personal Learning 2017, The AnyLogic Company North America.

27. Borshchev, A., The big book of simulation modeling: multimethod modeling with AnyLogic 6. 2013: AnyLogic North America.

28. Fanger, P.O., Thermal comfort. Analysis and applications in environmental engineering. Thermal comfort. Analysis and applications in environmental engineering., 1970.

29. Van Den Wymelenberg, K. and M. Inanici, A critical investigation of common lighting design metrics for predicting human visual comfort in offices with daylight. Leukos, 2014. 10(3): p. 145-164.

30. Rea, M.S., The IESNA lighting handbook: reference \& application. 2000.

31. EnergyPlus. Engineering Reference - EnergyPlus Documentation. 2018; Available from: https://energyplus.net/documentation.

32. EnergyPlus, EnergyPlus Downloads. 2017, U.S. Department of Energy (DOE). 